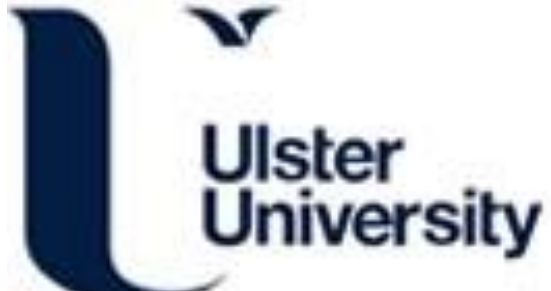

\section{Author Response: Passing-Bablok Regression Is Inappropriate for Assessing Association Between Structure and Function.}

Redmond, T., Russell, RA., Anderson, R., \& Garway-Heath, DF. (2013). Author Response: Passing-Bablok Regression Is Inappropriate for Assessing Association Between Structure and Function. Invest Ophthalmol Vis Sci, 54(8), 5850-5851.

Link to publication record in Ulster University Research Portal

Published in:

Invest Ophthalmol Vis Sci

Publication Status:

Published (in print/issue): 01/01/2013

\section{Document Version}

Publisher's PDF, also known as Version of record

\section{General rights}

Copyright for the publications made accessible via Ulster University's Research Portal is retained by the author(s) and / or other copyright owners and it is a condition of accessing these publications that users recognise and abide by the legal requirements associated with these rights.

\section{Take down policy}

The Research Portal is Ulster University's institutional repository that provides access to Ulster's research outputs. Every effort has been made to ensure that content in the Research Portal does not infringe any person's rights, or applicable UK laws. If you discover content in the Research Portal that you believe breaches copyright or violates any law, please contact pure-support@ulster.ac.uk. 


\section{Author Response: Passing-Bablok Regression Is Inappropriate for Assessing Association Between Structure and Function}

We thank Marin-Franch ${ }^{1}$ for his comments on our recent paper. $^{2}$ If some aspects of the statistical analysis were not as clear as they perhaps could have been, we are grateful for the opportunity to address them here.

The first concern was that our conclusion was in conflict with previous findings. ${ }^{3,4}$ Hood et al. ${ }^{3}$ assumed that there is no relationship between retinal nerve fiber layer thickness and visual field sensitivity in healthy observers; this was not a finding, but a working assumption. This point was made in our paper. On the other hand, Wollstein et al. ${ }^{4}$ suggested that substantial structural loss must occur in the retina before functional damage can be detected using current testing methods; however, other published data support the notion that retinal structure and visual function are associated in healthy eyes. ${ }^{5,6}$

Marin-Franch's second, and principal, concern is our use of Passing-Bablok regression analysis to test the null hypothesis that there was no association between retinal structure and visual function; he instead suggests that more insight would be gained from applying ordinary least squares (OLS) linear regression or Spearman's correlation. Firstly, we would like to point out that Marin-Franch has mistakenly applied the "method-equality" analysis outlined in Passing and Bablok ${ }^{7}$ in his simulations, rather than the transformation method, as outlined by Bablok et al., ${ }^{8}$ which we used in our analysis. Critically, for the derivation of the transformation regression procedure in Bablok et al., ${ }^{8}$ the authors state that it is necessary to start with the assumption of a positive correlation, as determined by Kendall's correlation, which is a similar, and an alternative, rank-based correlation method to Spearman's correlation, as proposed by Marin-Franch. When we performed

(a)

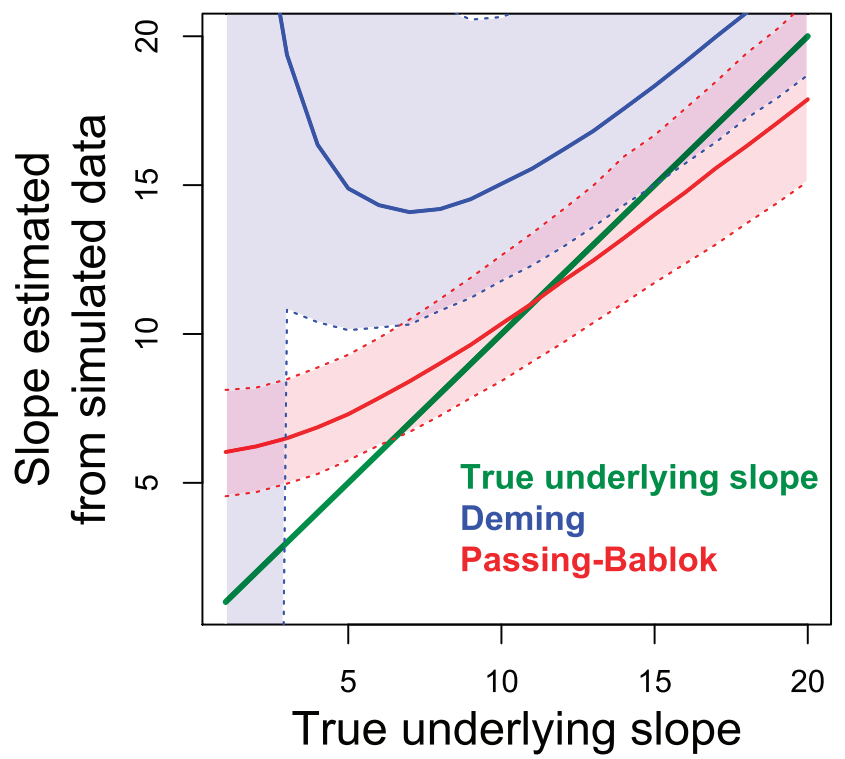
confidence intervals for each parameter are also shown (shaded regions).
Kendall's correlation test on our combined data, we did indeed find a significant association. Thus we felt it appropriate to use this technique. We regret that this point was not made in our paper, but it is clearly stated in the correct reference. ${ }^{8}$ In any case, inspection of Figures 2 through 4 in our paper ${ }^{2}$ reveals a striking similarity in the slopes of Passing-Bablok regression lines between hemifields and between healthy and glaucoma data, for most comparisons.

Is it better to use OLS here? We would argue that it is not. Warton et al. ${ }^{9}$ point out that it is inappropriate to use OLS when the variance in the $x$ - and $y$-variables differs and when noise is not Gaussian. Furthermore, they also state that an errors-in-variables method like major axis regression or standardized major axis regression should be used if one wishes to determine the slope parameter after establishing a significant association, which, as already pointed out, is an assumption of the method described by Bablok et al. ${ }^{8}$ Furthermore, part of our motivation for performing PassingBablok regression on our data came from analysis of 200,000 simulated data sets with Deming regression and PassingBablok regression. These simulated data sets comprised total deviation values (standard automated perimetry) and retinal nerve fiber layer thickness (optical coherence tomography), based on the data of Hood et al., ${ }^{3}$ and the aim was to determine how well each regression technique performed at estimating the true underlying slope in the simulated data. Marin-Franch and colleagues previously showed, ${ }^{10}$ also using simulations, that estimating linear relationships between structure and function measurements in glaucoma may be improved by the use of Deming regression compared with OLS, major-axis, and standardized major-axis regression techniques. However, unlike Passing-Bablok regression, Deming regression requires the investigator to input the ratio of variance in the two measurements of interest from population data. In practice, this information is often unavailable, as was the case for peripheral grating resolution acuity in our study; moreover, the variance ratio may change

(b)

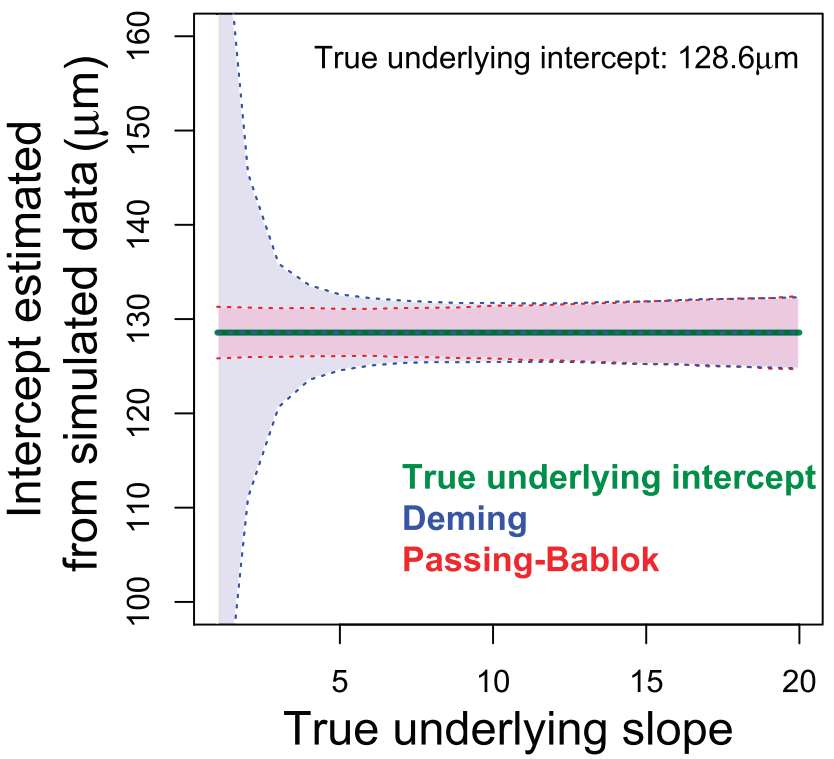

Figure. (a) Median slope and (b) median intercept estimates as a function of the true underlying slope in the simulated data (solid lines). The 95\% 
with the extent of damage. Figure (a) shows that for all simulations, Passing-Bablok regression yielded a slope parameter that was closer to the true underlying slope compared with that yielded by Deming regression (where the variance ratio was assumed to be equal to 1 ). The intercept parameter was estimated equally well with each technique, but the confidence interval was narrower for Passing-Bablok regression for all true underlying slopes (Fig. b). Moreover, performing Passing-Bablok regression on the data of Hood and Kardon ${ }^{11}$ for healthy observers (we initially find a significant Kendall's tau; $P<0.05$ following Holm-Bonferroni correction) reveals a slope of 13.7 and 18.7 for the upper and lower hemifields, respectively. One can see from Figure (a) that Passing-Bablok slopes in this region approximate the true underlying slope rather well.

It is clear that there is no "one-size-fits-all" approach to statistical line fitting and that the most appropriate regression technique varies with the form of the data and the validity of associated assumptions for those data. Marin-Franch has only simulated "no association," and has not compared the accuracy of OLS or Passing-Bablok slopes when there is a known association. In addition, he has not accounted for heteroskedasticity that is apparent in our data, a factor that may well affect the results of OLS, Deming, and Passing-Bablok regression, although Bablok et al. argue that their definition of regression coefficients as median values makes the method robust to the influence of extreme measurements. ${ }^{8}$

\section{Tony Redmond, ${ }^{1}$ Richard A. Russell, ${ }^{2}$ \\ Roger S. Anderson, ${ }^{3,4}$ David F. Garway-Heath ${ }^{2,3}$}

${ }^{1}$ Cardiff Centre for Vision Sciences, School of Optometry and Vision Sciences, Cardiff University, Cardiff, United Kingdom; ${ }^{2}$ Division of Optometry and Visual Sciences, City University London, London, United Kingdom; ${ }^{3}$ National Institute for Health Research (NIHR) Biomedical Research Centre at Moorfields Eye Hospital National Health Service (NHS) Foundation Trust and University College London (UCL) Institute of Ophthalmology, London, United Kingdom; and the ${ }^{4}$ School of Biomedical Sciences, University of Ulster, Coleraine, Northern Ireland, United Kingdom.

\section{Acknowledgments}

We thank Donald C. Hood for providing the raw data for healthy observers in Hood and Kardon's study. ${ }^{11}$

\section{References}

1. Marín-Franch I. Passing-Bablok regression is inappropriate for assessing association between structure and function in glaucoma. Invest Ophthalmol Vis Sci. 2013;54:5848-5849.

2. Redmond T, Anderson RS, Russell RA, Garway-Heath DF. Relating retinal nerve fiber layer thickness and functional estimates of ganglion cell sampling density in healthy eyes and in early glaucoma. Invest Ophthalmol Vis Sci. 2013;54:21532162.

3. Hood DC, Anderson SC, Wall M, Raza AS, Kardon RH. A test of a linear model of glaucomatous structure-function loss reveals sources of variability in retinal nerve fiber and visual field measurements. Invest Ophthalmol Vis Sci. 2009;50:42544266.

4. Wollstein G, Kagemann L, Bilonick RA, et al. Retinal nerve fibre layer and visual function loss in glaucoma: the tipping point. Br J Ophthalmol. 2012;96:47-52.

5. Garway-Heath DF, Holder GE, Fitzke FW, Hitchings RA. Relationship between electrophysiological, psychophysical, and anatomical measurements in glaucoma. Invest Ophthalmol Vis Sci. 2002;43:2213-2220.

6. Swanson WH, Felius J, Pan F. Perimetric defects and ganglion cell damage: interpreting linear relations using a two-stage neural model. Invest Ophthalmol Vis Sci. 2004;45:466-472.

7. Passing H, Bablok W. A new biometrical procedure for testing the equality of measurements from two different analytical methods. Application of linear regression procedures for method comparison studies in clinical chemistry, part I. J Clin Chem Clin Biochem. 1983;21:709-720.

8. Bablok W, Passing H, Bender R, Schneider B. A general regression procedure for method transformation. Application of linear regression procedures for method comparison studies in clinical chemistry, part III. J Clin Chem Clin Biochem. 1988;26:783-790.

9. Warton DI, Wright IJ, Falster DS, Westoby M. Bivariate linefitting methods for allometry. Biol Rev Camb Philos Soc. 2006; 81:259-291.

10. Marín-Franch I, Malik R, Crabb DP, Swanson WH. Choice of statistical method influences apparent association between structure and function in glaucoma. Invest Ophthalmol Vis Sci. 2013;54:4189-4196.

11. Hood DC, Kardon RH. A framework for comparing structural and functional measures of glaucomatous damage. Prog Retin Eye Res. 2007;26:688-710.

Citation: Invest Ophthalmol Vis Sci. 2013;54:5850-5851. doi:10.1167/iovs.13-13013 